\title{
SITUAÇÃO DOS JOVENS FRENTE AO MERCADO DE TRABALHO NO BRASIL ENTRE 2014 A 2017
}

\author{
Maria do Socorro Rodrigues Silva ${ }^{1}$, Jeferson de Castro Vieira² \\ ${ }^{1}$ Administradora, Professora Especialista no Centro Universitário de Goiás Uni- \\ ANHANGUERA, Mestranda em Desenvolvimento e Planejamento Territorial na \\ Pontifícia Universidade Católica de Goiás, Goiânia, Brasil. \\ m_socorr0@hotmail.com \\ 2 Economista, Mestre e Doutor em Estudos Comparados Sobre as Américas pela \\ Universidade de Brasília, Professor Doutor da Pontifícia Universidade Católica de \\ Goiás - PUC-Goiás, Goiânia, Brasil. \\ Recebido em: 06/04/2019 - Aprovado em: 10/06/2019 - Publicado em: 30/06/2019 \\ DOI: 10.18677/EnciBio_2019A191
}

\begin{abstract}
RESUMO
Há em curso, profundas transformações no sistema produtivo mundial com inovações nos segmentos organizacionais, financeiros e tecnológicos das empresas, que afetam, sobremaneira, o mercado de trabalho, especialmente para os jovens. $\mathrm{Na}$ fase de transição entre a formação educacional e profissional, marcada pelo forte avanço tecnológico e a busca pelo primeiro emprego, emerge uma categoria de jovens que não estudam e nem trabalham. O objetivo deste artigo foi analisar a estrutura da categoria de jovens "nem-nem" no período de 2014 a 2017. As variáveis utilizadas foram sexo, cor ou raça, faixas etárias, nível de escolaridade, condição na unidade domiciliar, motivos de não conseguir trabalho, rendimento domiciliar per capita, no Brasil e regiões geoeconômicas. Baseou-se nos dados da Pesquisa Nacional por Amostra de Domicílios do Instituto Brasileiro de Geografia e Estatística. Houve aumento de mulheres brancas, pretas e pardas que nem trabalham e nem estudam entre os anos de 2014 a 2017. Verificou-se um aumento da taxa da população "nem-nem" dos grupos entre 18 a 24 e de 25 a 29 anos no Brasil e regiões geoeconômicas. Concluiu-se ser imprescindível o desenvolvimento de políticas que contemplem mudanças na estrutura curricular educacional a fim de inserir no currículo propostas inovadoras de capacitações profissionalizantes dos jovens de baixa renda.
\end{abstract}

PALAVRAS-CHAVE: Conhecimento, Jovens, Mercado de Trabalho.

\section{SITUATION OF YOUNG PEOPLE AGAINST THE LABOR MARKET BETWEEN 2014 TO 2017}

\begin{abstract}
There are ongoing, deep transformations in the global production system with innovations in the organizational, financial and technological segments of companies, which greatly affect the labor market, especially for young people. In the transition phase between educational and professional formation, marked by strong
\end{abstract}


technological advancement and the search for the first job, a category emerges from young people who do not study nor work. The objective of this article is to analyze the structure of the category of youth "neither-nor" in the period from 2014 to 2017. The variables used were sex, color or race, age groups, schooling level, condition in home unit, reasons for not achieving labor, per capita household income, in Brazil and geoeconomic regions. It was based on data from the National Survey by Household Sample of the Brazilian Institute of Geography and Statistics. There was an increase in white, black and brown women who neither work nor study between the years 2014 to 2017 . There was an increase in the rate of the population "neithernor" of the groups between 18 to 24 and 25 to 29 years in Brazil and geoeconomic regions. It was concluded that the development of policies that contemplate changes in the curricular structure of education in order to insert innovative proposals for the vocational training of low-income youths is essential.

KEYWORDS: Knowledge, Youth, Labor Market.

\section{INTRODUÇÃO}

O século XXI é marcado por profundas transformações no sistema produtivo mundial. Há em curso, em razão do acelerado avanço tecnológico, uma geração de novos produtos e serviços, novos mercados e formas de organização produtiva, promovidos pela inovação em busca do desenvolvimento econômico (MAIA, 2019).

Assim, as mudanças na organização do capital em nível internacional, inovação nas tecnologias de informações e comunicações, organizações em redes, disseminação do neoliberalismo na economia mundial, favorece o processo de globalização econômica (HAFFNER et al, 2016).

Neste contexto da globalização, com a financeirização das economias, a explicação para as novas formas de riqueza contemporânea, a informação e o conhecimento passam a atuar como força produtiva determinante ou como capitalismo do conhecimento e estratégia de produção das sociedades modernas (PEREIRA, 2018).

O conhecimento, quando valorado pelo trabalho intelectual, privilegia a sociedade. Gois (2017), aponta que dentro da expansão do trabalho intelectual na produção, a força deste trabalho demanda inovações, tornando-a cada vez mais subordinada a uma produção crescente de conhecimento que se converte em mercadoria e capital, bem como, participante do processo de criação de valores.

Isto implica que a busca por conhecimento, sob o ponto de vista históricoontológico do trabalho, diz respeito à constituição do ser social, a partir do desenvolvimento de suas formas naturais e sociais. Em linhas gerais, isso significa que o trabalho forma o homem, que este se educa pelo ato de trabalhar. Assim, o sentido ontológico do trabalho expressa que é no próprio processo histórico de tornar-se humano que surge a atividade denominada trabalho, como algo específico do homem (FRIGOTTO, 2015).

Entretanto, nas últimas décadas do século $X X$, dada as transformações em curso, observou-se severas mudanças na centralidade da categoria trabalho, onde o controle rigoroso da produção em série e de massa são substituídos pela flexibilização da produção, por novos padrões de busca de produtividade, por novas formas de adequação da produção à lógica do mercado (ANTUNES, 2018).

Assim, a revolução tecnológica e a adoção de técnicas produtivas flexíveis, aliada à globalização e ao neoliberalismo contribuíram para a queda nos níveis de 
empregos formais, ou seja, grande parte do desemprego foi causado pela incorporação de tecnologia poupadora de mão de obra (RIBEIRO, 2016).

Neste contexto de novas qualificações, globalização, os jovens deparam-se com um mercado de trabalho cada vez mais restrito. Conforme o IPEA (2016), a população mais afetada pelo desemprego é a de jovens entre 14 e 24 anos, sendo que no $4^{\circ}$ trimestre de 2015 era de $15,25 \%$ e passou para $26,36 \%$ no primeiro trimestre de 2016.

Desta forma, os estudos que tratam a temática da juventude relacionado ao trabalho, são consensuais em reconhecer como diversos e polêmicos são os critérios que delimitam este fenômeno social (CORROCHANO, 2016). Neste aspecto, esta temática enfrenta problemas de definição, como, por exemplo, na denominação do objeto.

Os questionamentos vão desde quem são os jovens, passam pela faixa etária a que está se referindo, deparam-se pelo fato de serem ricos ou pobres e terminam com o nível de escolaridade formal concluída. Considerando a pluralidade desta categoria, gera inquietação o fato de uma parcela dos jovens estar afastada das escolas e do mercado de trabalho, dado que a juventude é um período crucial para a formação educacional e profissional dos indivíduos (MONTEIRO, 2013).

Diversos são os estudos que tratam o fenômeno "nem-nem", como os de Camarano e Kanso (2012), destacam que os "nem-nem" estão mais presentes nas famílias com menores faixas de renda per capita e com forte dependência da renda do chefe do domicilio; Cardoso (2013) estuda a crise econômica e a pobreza como problema social causador da condição "nem-nem"; Tillmann e Comim (2016), abordam a desigualdade social, escolaridade e rendimentos dos jovens no Brasil.

Trata-se, portanto, de uma geração que nem estuda nem trabalha, na faixa etária entre 15 e 29 anos. Para conceituar essa categoria, pode-se chegar à definição de que o denominado "nem-nem" é um jovem de baixa renda, com idade entre 16 e 29 anos, que não está inserido no mercado formal de trabalho, não frequenta estabelecimento de ensino regular, não concluiu o Ensino Fundamental ou Ensino Médio e não exerce nenhuma atividade conceituada como trabalho (BARBOSA, 2017).

Entretanto, a categoria "nem-nem" é inapropriada, não representando a realidade dos jovens brasileiros enquadrados fora do mercado formal de trabalho, não atingindo a perspectiva traçada pela sociedade sobre a trajetória educacional e trabalhista. Isso não representa o modelo de classe média, nem corresponde as condições oferecidas aos jovens mais pobres da população brasileira. $\mathrm{O}$ que falta a esse jovem não é apenas emprego formal e ensino regular, mas toda uma estrutura socioeconômica, incluindo alimentação, saúde, transporte, educação, segurança e empregos dignos (BARBOSA, 2017).

Constata-se que os jovens "nem-nem" estão mais expostos aos riscos sociais, dependem da rede pública de educação para suas formações profissionais, e por diversos motivos, os quais variam segundo diferenciais de faixa etária, exposição à vulnerabilidade e de gênero, abandonam os estudos dificultando a inserção no mercado de trabalho, aumentando as desigualdades sociais (DIAS, 2016).

Assim, o sistema educacional necessita de mudanças que contemplem novo formato de capacitação dos jovens, objetivando a redução da evasão escolar. A relevância da articulação entre a formação geral e a formação profissional, fortemente defendida pelos trabalhadores da educação e intelectuais comprometidos 
na área de Educação e do Trabalho no Brasil, desde as últimas décadas do século XX, resultou na elaboração do Decreto 5.154/2004 (BRASIL,2004), sendo política e pedagogicamente necessário, uma vez que o processo de formação profissional não se restringe à formação para o mercado de trabalho, posto que os trabalhadores necessitam dominar os conhecimentos teóricos e operacionais a fim de compreender e dominar os processos de trabalho (BELMIRO, 2018).

Assim, pode-se afirmar que a juventude é um período de transição entre formação educacional e profissional, sendo esta transição marcada pelo forte avanço das tecnologias que modificam o mercado de trabalho e, por consequência, geram novas demandas no campo da educação e qualificação profissional, causando incertezas e inseguranças aos jovens. Tendo como referências essas transformações do mundo do trabalho, este artigo buscou analisar a estrutura da categoria de jovens nem estudam e nem trabalham no período de 2014 a 2017.

\section{Objeto e amostra da pesquisa}

\section{MATERIAL E MÉTODOS}

Os objetos da pesquisa foram a taxa da população que nem estuda nem trabalha, perfis da população por sexo, raça, frequência escolar da população residente e renda per capita familiar. A base de dados utilizada foi a Pesquisa Nacional por Amostra de Domicílios Contínua (PNAD) do Instituto Brasileiro de Geografia e Estatística (IBGE), no período de 2014 a 2017, no Brasil e suas regiões geoeconômicas.

\section{Classificação da pesquisa}

Para a classificação da pesquisa recorreu-se ao método adotado por Severino (2016), que qualifica a pesquisa em aspectos quanto aos fins e aos meios. Quanto aos fins, a pesquisa foi descritiva e exploratória. Na parte descritiva houve uma caracterização da amostra e suas variáveis, contribuindo para melhor descrever os fatos. Já na parte exploratória, abordou-se uma análise da categoria de jovens, denominada "nem-nem", traçando perfis juvenis e refletindo sobre o mercado de trabalho nos anos de 2014 a 2017.

Quanto aos meios, tratou-se de referências e análise dos dados estatísticos. Neste aspecto, para a fundamentação teórica investigou-se artigos científicos, livros e revistas especializadas.

\section{Variáveis}

As variáveis utilizadas para identificar os perfis da população foram: sexo, cor ou raça, faixas etárias, nível de escolaridade, condição na unidade domiciliar e trabalho; já para a frequência escolar as variáveis utilizadas foram as três primeiras citadas anteriormente, incluindo o rendimento domiciliar per capita; para a taxa da população foi a faixa etária e as cinco regiões do Brasil, sendo: Norte, Nordeste, Sudeste, Sul e Centro-Oeste. A seleção da variável "renda" foi realizada com base em indicadores de estudos semelhantes que apontam uma concentração de jovens "nem-nem" nos estratos de renda mais baixos do país.

O IBGE (2017), define frequência escolar, na semana de referência, curso pré-escolar, curso regular do ensino fundamental, regular do ensino médio, superior de graduação, educação de jovens e adultos ou supletivos do ensino fundamental, educação de jovens e adultos ou supletivos do ensino médio, alfabetização de 
jovens e adultos, pré-vestibular, mestrado ou doutorado. A semana de referência é a semana de domingo a sábado, precedida pela semana de entrevista da Pesquisa Nacional por Amostra de Domicílios Contínua (PNAD), esse período é utilizado, como por exemplo, na captação de informações sobre pessoas ocupadas, dias e horas trabalhados efetivamente, dedicação à atividade de produção para o próprio consumo e construção para o próprio uso, e dedicação à atividade de cuidado de pessoas.

As características das variáveis dos perfis da população foram: sexo feminino e masculino, cor dos jovens, sendo homens brancos, pretos ou pardos e mulheres brancas, pretas ou pardas; nível de escolaridade inclui o fundamental incompleto, fundamental completo e médio incompleto, médio completo ou mais elevado, pessoa de referência, cônjuge, filho, outro parente ou agregado (condição da unidade familiar).

O IBGE (2018) divide a faixa etária em vários subgrupos: 6 a 10,11 a 14, 15 a 17,18 a 24 e 25 a 29 anos, classificando-se como jovem a parcela da população situadas nestas três últimas faixas etárias. Neste estudo, as faixas etárias utilizadas para analisar os perfis da população foram: 18 a 24, 25 a 29 anos e a frequência escolar: 15 a 17,18 a 24 anos.

\section{Apresentação e análise de dados}

Os dados coletados foram organizados em quatro tabelas, para avaliar os perfis da população e a frequência escolar, incluindo variáveis e as respectivas características. A primeira tabela foi organizada descrevendo o perfil por sexo, cor ou raça, nível de escolaridade e condição na unidade familiar da população "nemnem", na segunda tabela apresentou-se os motivos de não conseguir trabalho, na terceira tabela expôs-se os dados sobre a frequência escolar da população residente, na quarta tabela apresentou-se a distribuição da população "nem-nem" nas cinco regiões do Brasil. Nas tabelas 1 e 4 foram utilizados dados amostrais dos anos de 2014 a 2017, já as tabelas 2 e 3 constaram os anos de 2016 e 2017.

O IBGE (2017) define posição na ocupação como, a relação de trabalho existente entre a pessoa e o empreendimento em que trabalha. A classificação é dividida em: empregado, trabalhador doméstico, autônomo, empregador, trabalhador não remunerado membro da unidade domiciliar, outro trabalhador não remunerado, trabalhador na produção para o próprio consumo, ou trabalhador na construção para o próprio uso. Para efeito de divulgação, as categorias "trabalhador não remunerado membro da unidade domiciliar" e "outro trabalhador não remunerado" são reunidas em uma única, denominação "não remunerado".

Analisaram-se dados da primeira tabela, fazendo comparações entre os anos de 2014 a 2017 relacionadas as características das variáveis. Na segunda tabela, analisou-se a característica sexo dos indivíduos (masculino e feminino), comparando-se os maiores e menores valores, relacionando os motivos de não conseguirem trabalho ou que estavam aguardando respostas das iniciativas de buscarem trabalhos, entre os anos de 2016 e 2017. Na terceira tabela houve comparações da frequência escolar dos grupos entre 15 a 17 anos e de 18 a 24 anos, no ensino médio e superior, entre os anos de 2016 e 2017, relacionado ao rendimento real efetivo domiciliar. Por fim, na quarta tabela analisou-se as taxas da população "nem-nem", o maior e o menor valor entre as cinco regiões do Brasil no período de 2014 a 2017. 


\section{RESULTADOS E DISCUSSÕES}

Conforme demonstrado na Tabela 1, houve aumento de mulheres brancas, pretas e pardas que nem trabalham e nem estudam entre os anos de 2014 e 2017, sendo de $26 \%, 29,6 \%, 38 \%$ e $41 \%$, respectivamente. Em relação ao nível de escolaridade da população de 18 a 29 anos ocorreu aumento de jovens sem instrução ou com fundamental incompleto, sendo 2017 o ano com maior percentual $(46,1 \%)$, acarretando déficit na educação. De acordo com o IBGE (2017), a posição no domicílio foi enquadrada como trabalhador não remunerado da unidade domiciliar: a pessoa de referência, cônjuge, filho e outro parente. Com relação a condição na unidade familiar, aconteceu redução como cônjuge de 2014 (44,8\%), 2015 (45,7\%), 2016 (44,1\%) e 2017 (42,1\%).

TABELA 1. Perfil da população que "nem- nem" de 18 a 29, por sexo, cor ou raça e posição no domicílio, 2014 -2017, Brasil.

\begin{tabular}{|c|c|c|c|c|}
\hline \multirow{2}{*}{ Características } & \multicolumn{4}{|c|}{ Ano } \\
\hline & 2014 & 2015 & 2016 & 2017 \\
\hline Sexo e Cor ou raça & \multicolumn{4}{|c|}{$\%$} \\
\hline Homem branco & 15,1 & 16,6 & 20,4 & 19,4 \\
\hline Homem preto e pardo & 19,0 & 21,4 & 25,9 & 25,9 \\
\hline Mulher branca & 26,0 & 28,0 & 28,6 & 29,6 \\
\hline Mulher preta e parda & 38,0 & 40,5 & 42,3 & 41,0 \\
\hline Nível de escolaridade & \multicolumn{4}{|c|}{$\%$} \\
\hline Sem instrução ou fundamental incompleto & 37,8 & 40,1 & 45,8 & 46,1 \\
\hline Fundamental completo e médio incompleto & 23,1 & 25,6 & 26,5 & 27,0 \\
\hline Médio completo ou mais elevado & 22,1 & 24,7 & 27,8 & 27,3 \\
\hline Condição na unidade familiar & \multicolumn{4}{|c|}{$\%$} \\
\hline Pessoa de referência & 19,3 & 21,2 & 24,7 & 25,3 \\
\hline Cônjuge & 44,8 & 45,7 & 44,1 & 42,1 \\
\hline Filho & 21,9 & 24,8 & 28,2 & 28,0 \\
\hline Outro parente ou agregado & 26,0 & 27,0 & 31,4 & 31,1 \\
\hline
\end{tabular}

Fonte: IBGE, (2017) adaptado pelos autores.

Conforme demonstrado na Tabela 2, no ano de 2016 os motivos de não conseguirem trabalho, menos pontuados para os homens foram: tinham que cuidar de afazeres domésticos $(1,4 \%)$ e não conseguiam trabalho por serem muito jovens $(2,5 \%)$; para as mulheres foram: não conseguiam trabalho por serem muito jovens $(1,8 \%)$ e não tinham experiências profissionais ou qualificações $(3,5 \%)$. Os motivos de maiores pontuações em 2016 e 2017 para os homens foram: não haviam trabalhos na localidade (44,3\% e $45,4 \%$ ) e outros motivos (20,8\% e $20,8 \%$ ); para as mulheres foram: tinham que cuidar dos afazeres domésticos $(34,6 \%$ e $35,4 \%)$ seguido do motivo não haviam trabalhos na localidade $(32,1 \%$ e $32,1 \%)$ e outros motivos aparecem com pontuações relevantes entre 2016 e 2017 (15,6\% e 15,1\%). Segundo Pochmann (2015), no Brasil, por suas características demográficas, o desemprego juvenil é, e sempre foi mais alto que os adultos e idosos. Para Mota (2018), o processo de transição da fase jovial para a vida adulta mostra um forte viés de gênero, de forma genérica, homens aparentam mais associados ao mercado de trabalho e as mulheres às tarefas domésticas. 
TABELA 2. Motivos dos jovens "nem-nem" não conseguirem trabalho de 18 a 29 anos, segundo as características sexo, cor ou raça, (2016-2017), Brasil.

\begin{tabular}{l|l|l|l|l}
\hline \multirow{2}{*}{ Motivo } & \multicolumn{2}{c|}{ Sexo } & \multicolumn{3}{c}{ Cor ou Raça } \\
\cline { 2 - 5 } & \multicolumn{1}{c}{ Homem (\%) } & Mulher (\%) & Branco (\%) & Preto/ Pardo (\%) \\
\hline & 2016 & & & \\
Aguardando resposta de medida para conseguir trabalho & 13,7 & 6,2 & 9,2 & 8,5 \\
Não conseguia trabalho adequado & 11,4 & 6,2 & 9,3 & 7,4 \\
Não tinha experiência profissional ou qualificação & 5,9 & 3,5 & 3,6 & 4,5 \\
Não conseguia trabalho por ser muito jovem & 2,5 & 1,8 & 3,1 & 1,7 \\
Não havia trabalho na localidade & 44,3 & 32,1 & 26,8 & 39,6 \\
Tinha que cuidar dos afazeres domésticos & 1,4 & 34,6 & 22,8 & 24,0 \\
Outros motivos & 20,8 & 15,6 & 25,2 & 14,3 \\
& 2017 & & & \\
Aguardando resposta de medida para conseguir trabalho & 11,6 & 4,9 & 8,2 & 6,9 \\
Não conseguia trabalho adequado & 10,9 & 7,0 & 10,0 & 7,8 \\
Não tinha experiência profissional ou qualificação & 7,4 & 4,0 & 5,7 & 5,0 \\
Não conseguia trabalho por ser muito jovem & 2,7 & 1,5 & 2,3 & 1,8 \\
Não havia trabalho na localidade & 45,4 & 32,1 & 28,7 & 39,6 \\
Tinha que cuidar dos afazeres domésticos & 1,2 & 35,4 & 24,3 & 23,1 \\
Outros motivos & 20,8 & 15,1 & 20,8 & 15,8 \\
\hline
\end{tabular}

Fonte: IBGE, (2017) adaptado pelos autores.

$\mathrm{Na}$ Tabela 3, apresentam-se os dados sobre a frequência escolar de acordo com o rendimento domiciliar per capita, para os grupos entre 15 a 17 anos no ensino médio e entre 18 a 24 anos no ensino superior, tanto mulheres quanto homens brancos e pretos, nos anos de 2016 e 2017. Desse modo, observaram-se diferenças expressivas, como por exemplo, no ano de 2016, para a variável rendimento domiciliar per capita Q1- apenas 53,8\% dos indivíduos entre 15 a 17 anos frequentavam o ensino médio e $6,6 \%$ dos indivíduos frequentavam o ensino superior da população jovem entre 18 a 24 anos. No ano de 2017, para a variável rendimento domiciliar per capita Q5 90,5\% dos indivíduos entre 15 a 17 anos frequentavam o ensino médio e 58,3\% entre 18 a 24 anos frequentavam o ensino superior. Figueiredo e Almeida (2017) afirmam que o perfil de renda é um forte indicador para compreender o comportamento dos jovens que não estudam e não trabalham. Assim, existem duas possibilidades para explicar os obstáculos no acesso e permanência na escola: indivíduos oriundos de famílias de baixa renda e indivíduos que, independentemente da família de origem, têm baixa renda por estarem constituindo família. 
TABELA 3. Frequência escolar da população residente de 15 a 24 anos, por sexo, cor ou raça, por faixas etárias, nível de escolaridade, rendimento domiciliar per capita, 2016-2017, Brasil.

\begin{tabular}{|c|c|c|c|c|}
\hline \multirow[t]{2}{*}{ Variáveis e Características } & \multicolumn{2}{|c|}{$\begin{array}{c}15 \text { a } 17 \text { anos, no } \\
\text { ensino médio }\end{array}$} & \multicolumn{2}{|c|}{$\begin{array}{l}18 \text { a } 24 \text { anos, no } \\
\text { ensino superior }\end{array}$} \\
\hline & 2016 & 2017 & 2016 & 2017 \\
\hline Sexo & \multicolumn{4}{|c|}{ Unidade (\%) } \\
\hline Homem & 63,2 & 63,6 & 20,0 & 19,7 \\
\hline Mulher & 73,5 & 73,7 & 27,8 & 26,8 \\
\hline \multicolumn{5}{|l|}{ Cor ou raça } \\
\hline Branca & 75,9 & 76,6 & 33,5 & 32,9 \\
\hline Preta ou parda & 63,1 & 63,5 & 16,8 & 16,7 \\
\hline \multicolumn{5}{|l|}{ Rendimento domiciliar per capita } \\
\hline Quintil 1 - Até 20\% & 53,8 & 54,7 & 6,6 & 6,6 \\
\hline Quintil 2 - Mais de $20 \%$ até $40 \%$ & 64,6 & 65,3 & 12,0 & 12,0 \\
\hline Quintil 3 - Mais de $40 \%$ até $60 \%$ & 73,6 & 73,9 & 19,9 & 20,1 \\
\hline Quintil 4 - Mais de $60 \%$ até $80 \%$ & 82,1 & 81,1 & 32,1 & 32,3 \\
\hline Quintil 5 - Mais de $80 \%$ & 89,6 & 90,7 & 60,2 & 58,3 \\
\hline
\end{tabular}

Fonte: IBGE, (2017) adaptado pelos autores.

Conforme os dados apresentados na Tabela 4, verificou-se crescimento da população "nem-nem", entre os anos de 2014 a 2017, por região geoeconômica do Brasil. Comparando os anos de 2014 a 2017 apenas no Brasil, ou seja, visão geral do país, houve aumento da referida categoria sendo que no ano de 2014 foi de $25,0 \%$ para $30,1 \%$ em 2016 na faixa etária entre 18 a 24 anos; de 23,8\% em 2014 para $26,4 \%$ em 2017 para o grupo entre 25 a 29 anos. Segundo o IPEA (2018), a geração "nem-nem" está crescendo, sendo que $23 \%$ (dois em cada dez) dos jovens brasileiros não trabalham nem estudam, ressaltando que a maior parte desta geração são mulheres de baixa renda e os motivos para este significativo percentual de jovens "nem-nem" são problemas com habilidades cognitivas e socioemocionais, falta de políticas públicas, obrigações familiares com parentes e filhos, dentre outras questões. 
TABELA 4. Taxa da População "nem-nem" de 18 a 29 anos apenas no Brasil e suas regiões - 2014 a 2017.

\begin{tabular}{|c|c|c|c|c|}
\hline & \multicolumn{2}{|c|}{2014} & \multicolumn{2}{|c|}{2016} \\
\hline \multirow{2}{*}{$\begin{array}{c}\text { Faixa etária } \\
\text { Unidade }\end{array}$} & 18 a 24 anos & 25 a 29 anos & 18 a 24 anos & 25 a 29 anos \\
\hline & \multicolumn{4}{|c|}{$\%$} \\
\hline Brasil & 25,0 & 23,8 & 30,1 & 25,8 \\
\hline \multicolumn{5}{|l|}{ Regiões } \\
\hline Norte & 27,6 & 28,4 & 32,2 & 29,5 \\
\hline Nordeste & 30,6 & 30,2 & 36,9 & 34,0 \\
\hline Sul & 18,9 & 16,1 & 21,8 & 17,1 \\
\hline Sudeste & 23,1 & 21,7 & 28,5 & 23,2 \\
\hline Centro Oeste & 21,5 & 20,2 & 25,5 & 22,7 \\
\hline & \multicolumn{2}{|c|}{2015} & \multicolumn{2}{|c|}{2017} \\
\hline Unidade & \multicolumn{4}{|c|}{$\%$} \\
\hline Brasil & 27,3 & 24,5 & 29,8 & 26,4 \\
\hline \multicolumn{5}{|l|}{ Regiões } \\
\hline Norte & 30,5 & 28,5 & 33,6 & 29,8 \\
\hline Nordeste & 32,9 & 29,8 & 36,9 & 35,8 \\
\hline Sul & 19,8 & 15,9 & 20,6 & 18,4 \\
\hline Sudeste & 25,9 & 23,0 & 28,2 & 22,6 \\
\hline Centro Oeste & 23,0 & 23,2 & 24,2 & 23,8 \\
\hline
\end{tabular}

Fonte: IBGE (2017), adaptado pelos autores.

Ainda na tabela 4, a região geoeconômica que apresentou as menores taxas da população "nem-nem" foi a Região Sul sendo de 18,9\% para o grupo entre $18 \mathrm{e}$ 24 anos em 2014 e de 15,9\% para o grupo entre 25 e 29 anos em 2015. A região que apresentou maiores taxas da população "nem-nem" foi a Região Nordeste, sendo de 30,6\% (2014) para 36,9\% (2017) para o grupo entre 18 a 24 anos e de $30,2 \%$ (2014) para 35,8\% (2017) para o grupo entre 25 a 29 anos. Esta categoria representa uma parcela significativa da população e a inatividade pode gerar sérios prejuízos à capacidade produtiva desta população por não estar em busca de capacitação e experiência, requisito básico do mercado de trabalho contemporâneo. $\mathrm{Na}$ economia globalizada, é fundamental preparar os jovens para o mercado de trabalho, criar meios e ferramentas para que o jovem busque a si mesmo e desafie a sua própria inteligência e, nesta direção, a educação formal deve proporcionar as melhores condições de formação (BIASOTTO, 2016).

\section{CONCLUSÃO}

Conclui-se que a categoria dos jovens brasileiros independentemente da cor/raça, sexo, nível de escolaridade, regiões do Brasil, enfrenta o desemprego por vários motivos. Em 2014 a 2017 piorou o nível de escolaridade do perfil da população de 18 a 29 anos, ainda ocorreu diferenças expressivas no rendimento domiciliar per capita para todas as faixas consideradas jovens. $O$ fato de não estarem trabalhando incluiu não ter trabalho na localidade, cuidar dos afazeres domésticos e por ser muito jovem, foram os motivos para essa situação no período de 2016 e 2017. 
Em todos os níveis de escolaridade a educação profissional, deve estar integrada à educação básica de maneira a complementá-la e não substituí-la. A sugestão para melhorias é investir em treinamentos, qualificação, cursos, módulos de diversos assuntos, visando o estabelecimento de diretrizes formativas às diversas especialidades ou ocupações relativas aos setores da economia e viabilizar a ascensão do nível de escolaridade/capacitação profissional dos jovens para realizar uma transição bem-sucedida de seus estudos para o mercado de trabalho.

São necessárias as implementações das políticas públicas para solucionar problemas, a instituição escolar acompanhar transformações e conscientizar os jovens brasileiros para conduzir a uma formação integrada ao trabalho e demais processos que os permeiam com metodologias ativas para uma educação inovadora. A melhora de serviços e os subsídios para o transporte e uma maior oferta de creches, para que as mulheres possam conciliar trabalho e estudo com os afazeres domésticos, são políticas que podem ser efetivadas.

\section{REFERÊNCIAS}

ANTUNES, Ricardo. ADEUS AO TRABALHO?: ensaio sobre as metamorfoses e a centralidade no mundo do trabalho. 16 ${ }^{a}$ edição. São Paulo: Cortez, 2018.

BARBOSA, R. B. "nem-nem": uma subcategoria de juventude ou uma ficção? 2017.166f. Dissertação (Mestrado em Sociologia), Setor de Ciências Humanas, Letras e Artes, Universidade Federal do Paraná, 2017.

BELMIRO, C.M.B. Juventude e formação profissional a partir da reestruturação produtiva do capital no século XX: uma análise sobre o Programa Jovem Aprendiz da Cidade de Monte Carmelo (2016-2018). Dissertação (Mestrado em Educação), Programa de Pós-Graduação em Educação, Universidade Federal de Uberlândia, 2018.

BIASOTTO, H. O contexto do mercado de trabalho contemporâneo: contribuição da metodologia ontopsicológica para a formação da competência de jovens. In: Congresso Internacional Uma Nova Pedagogia para a Sociedade Futura, 2. 2016. Centro Internacional de Arte e Cultura Humanista Recanto Maestro. Anais... Uma Nova Pedagogia para a Sociedade Futura: Faculdade Antônio Meneghetti, 2016, p. 263-274. Disponível em: https://reciprocidade.emnuvens.com.br/novapedagogia/article/view/164>.

BRASIL. Ministério da Educação. Decreto no 5.154, de 23 de julho 2004. Regulamenta o $\S 2^{\circ}$ do art.36 e os arts. 39 e 41 da Lei no 9.394 , de 20 de dezembro de 1996, que estabelece as diretrizes e bases da educação nacional, e dá outras providências. Disponível em: <http:www.planalto.gov.br/ccivil_03/_ato20042006/2004/decreto/D5154.htm>.

CAMARANO, A.A.; KANSO, S. O que estão fazendo os jovens que não estudam, não trabalham e não procuram trabalho? Boletim do Mercado de Trabalho. Conjuntura e Análise, Rio de Janeiro, v.53, p.37-44 nov.2012. Disponível em: http://repositorio.ipea.gov.br/bitstream/11058/3855/1/bmt53 nt03 jovens. 
CARDOSO, A. Juventude, Trabalho e Desenvolvimento: elementos para uma agenda de investigação. CADERNO CRH, Salvador: UFBA, v. 26, n. 68, pp. 293314, maio/ago.,2013. Disponível em: http://dx.doi.org/10.1590/S010349792013000200006.

CORROCHANO, M.C; ABRAMO, L.W. Juventude, educação e trabalho decente: a construção de uma agenda. Linhas Críticas, Brasília-DF. v.22. n.47. p.110-129. jan./abr.2016. Disponível em: http://www.redalyc.org/articulo.oa?id=193549427007 ISSN 1516-4896

DIAS, T.S. Entre ausências, incertezas e labirintos: a inserção social de jovens que não trabalham nem estudam no Brasil, 2016. Dissertação (Desenvolvimento, Sociedade e Cooperação Internacional) UNB. Brasília-DF, 2016.

FIGUEIREDO, A.M.R.; ALMEIDA, J.B.S.A. População "nem-nem": uma análise a partir dos dados da PNAD 2012. Revista de Estudos Sociais, n. 38, v. 19, p.106129, 2017. Doi: http://dx.doi.org/10.19093/res4942.

FRIGOTTO, G. Contexto e sentido ontológico, epistemológico e político da inversão da relação educação e trabalho para trabalho e educação. Revista Contemporânea de Educação, vol.10, n.20, julho/dezembro de 2015. Disponível em: https://revistas.ufrj.br/index.php/rce/article/view/2729.

GOIS, J.C. S. A ampliação do trabalho intelectual e o setor de serviços na conjuntura da reestruturação produtiva. In: Seminário Nacional de Serviço Social, Trabalho e Políticas Sociais, 2, 2017. Universidade Federal de Santa Catarina. Anais...Florianópolis: Repositório Institucional (UFSC), 2017, p.1-10. Disponível em: $<$ https://repositorio.ufsc.br/bitstream/handle/123456789/180047/102 00501.pdf?sequ ence $=1$ \&isAllowed $=\mathrm{y}>$.

HAFFNER, J.A.; SILVESTRE, J.M. Globalização financeira e desindustrialização no brasil. CADERNOS do DESENVOLVIMENTO, Rio de Janeiro, v.11, n.18, pp.55-77, jan./jun.2016. Disponível em: http://www.cadernosdodesenvolvimento.org.br/ojs2.4.8/index.php/cdes/article/view/76/78.

IPEA, Instituto de Pesquisa Econômica Aplicada. Carta de Conjuntura, n.31, junho de $2016 . \quad$ Disponível em: http://www.jpea.gov.br/portal/index.php?option=com content\&view=article\&id=27921 \&ltemid $=3$

Pesquisa revela que 20 milhões de jovens nem estudam nem trabalham na América Latina e no Caribe. 2018. Disponível em: < http://www.ipea.gov.br/portal/index.php?option=com content\&view=article\&id=34460 \&catid=10\&ltemid $=9>$.

IBGE, Instituto Brasileiro de Geografia e Estatística. Pesquisa Nacional por Amostra de Domicílios. Tabelas, Rio de Janeiro: IBGE, 2017. 
MAIA, C.M. Chapecó e cidades de influência: a constituição de uma região inteligente. In. ALMEIDA, G.G.F.; ENGEL, V. (Orgs.) Cidades inteligentes: desafios e oportunidades nas cidades do século XXI. Santa Cruz do Sul: The Help, 2019, p.64-78.

MONTEIRO, J. Quem são os Jovens Nem-Nem? Uma análise sobre os jovens que não estudam e não participam do mercado de trabalho. Texto para Discussão, n.34, FGV/lbre, 2013. Disponível em: http://hdl.handle.net/10438/11661

MOTA, D.G.F. Os jovens que nem trabalham nem estudam no Brasil: Caracterização e transformações no período 2004/2015. 2018.280f. Tese (Doutorado em Ciências, em Economia). Universidade Federal de Rio de Janeiro, Instituto de Economia, Rio de Janeiro, 2018.

PEREIRA, L.C.B. Capitalismo financeiro-rentista. Estudos Avançados. v.32, n. 92, p. 17-29, 2018. Disponível em: <http://dx.doi.org/10.5935/0103-4014.20180003 >. Doi:10.5935/0103-4014.20180003.

POCHMANN, M. Ajuste econômico e desemprego recente no Brasil Metropolitano. Revista Estudos Avançados, v.29, n.85, p.7-19, 2015. Disponível em: $<$ http://dx.doi.org/10.1590/S0103-40142015008500002 >. Doi: 10.1590/S010340142015008500002.

RIBEIRO, U.P. Inserção dos serviços nas políticas de desenvolvimento do governo do Estado de Sergipe no período recente. Revista do Curso de Direito, v.6, n.1, dezembro/2016. Faculdade de Administração e Negócios de Sergipe - Fanese Sergipe. Disponível em: $\quad$ http://app.fanese.edu.br/rd direito/wpcontent/uploads/2017/06/ulisses-revista-direito-6.1-2016.

SEVERINO, A.J. Metodologia do Trabalho Científico. 24a Ed. São Paulo: Cortez, 2016, 317p.

TILLMANN, E.A.; COMIM, F. Os determinantes da decisão entre estudo e trabalho dos jovens no Brasil e a geração "nem-nem". Revista Pesquisa e Planejamento Econômico, v.46, n.2, 2016. Disponível em: $<$ http://ppe.ipea.gov.br/index.php/ppe/article/viewFile/1629/1225>. 